\title{
Thermal Conductivity of Cu-Cr-Zr-Ti Alloy in the Temperature Range of 300-873 K
}

\author{
S. Chenna Krishna, ${ }^{1}$ N. Supriya, ${ }^{2}$ Abhay K. Jha, ${ }^{1}$ Bhanu Pant, ${ }^{1}$ \\ S. C. Sharma, ${ }^{1}$ and Koshy M. George ${ }^{3}$ \\ ${ }^{1}$ Materials and Metallurgy Group, Materials and Mechanical Entity, Vikram Sarabhai Space Centre, Trivandrum 695022, India \\ ${ }^{2}$ Analytical, Spectroscopy, and Ceramics Group, Propellants, Polymers, Chemicals, and Materials Entity, \\ Vikram Sarabhai Space Centre, Trivandrum 695022, India \\ ${ }^{3}$ Materials and Mechanical Entity, Vikram Sarabhai Space Centre, Trivandrum 695022, India
}

Correspondence should be addressed to S.Chenna Krishna, chenna.sk@gmail.com

Received 12 November 2012; Accepted 5 December 2012

Academic Editors: R. Hebert, P. Markovsky, and T. Yue

Copyright $\odot 2012$ S. Chenna Krishna et al. This is an open access article distributed under the Creative Commons Attribution License, which permits unrestricted use, distribution, and reproduction in any medium, provided the original work is properly cited.

In the present investigation, thermal conductivity of $\mathrm{Cu}-\mathrm{Cr}-\mathrm{Zr}$ - Ti alloy was determined as the product of the specific heat $\left(\mathrm{C}_{p}\right)$, thermal diffusivity $(\alpha)$, and density $(\rho)$ in the temperature range of $300-873 \mathrm{~K}$. The experimental results showed that the thermal conductivity of the alloy increased with increase in temperature up to $873 \mathrm{~K}$ and the data was accurately modeled by a linear equation. For comparison, thermal conductivity was also evaluated for OFHC copper in the same temperature range. The results obtained were discussed using electrical conductivity and hardness measurements made at room temperature. Transmission electron microscopy (TEM) was done to understand the microstructural changes occurring in the sample after the test. Wiedemann-Franz-Lorenz law was employed for calculating electronic and phonon thermal conductivity using electrical conductivity. On the basis of studies conducted it was deduced that in situ aging may be one of the reasons for the increase in thermal conductivity with temperature for $\mathrm{Cu}-\mathrm{Cr}-\mathrm{Zr}-\mathrm{Ti}$ alloy.

\section{Introduction}

$\mathrm{Cu}-\mathrm{Cr}-\mathrm{Zr}$ alloy is a candidate material for high heat flux applications like the inner wall of a thrust chamber and the first wall of nuclear reactor owing to its high conductivity and strength $[1,2]$. The high conductivity of the alloy is attributed to the low solubility of $\mathrm{Cr}$ and $\mathrm{Zr}$ in copper at room temperature [3], while the strength is due to the precipitation of $\mathrm{Cr}$ and $\mathrm{Cu}_{5} \mathrm{Zr}$ in copper matrix $[4$, 5]. Zirconium plays an additional role of fixing elemental sulphur and suppresses dynamic embrittlement [6]. The alloy used in the present study is modified by the addition of titanium of $\mathrm{Cu}-\mathrm{Cr}-\mathrm{Zr}$ alloy. Titanium plays a role similar to that of zirconium in $\mathrm{Cu}-\mathrm{Cr}-\mathrm{Zr}$ alloy in suppressing dynamic embrittlement by fixing elemental sulphur as titanium sulphide [7]. Limited literature is available on mechanical properties, microstructure and thermal properties of $\mathrm{Cu}-\mathrm{Cr}-$ Zr-Ti alloy. Lack of thermal conductivity data for the alloy at elevated temperature promoted us to design experiments to evaluate the same in the temperature of $300-873 \mathrm{~K}$.

\section{Experimental Procedure}

Hot rolled and annealed plate of $\mathrm{Cu}-0.61 \mathrm{Cr}-0.038 \mathrm{Zr}$ $0.029 \mathrm{Ti}-0.003 \mathrm{Fe}$ (wt \%) alloy was used in the present study. Small pieces cut from the plate were used for hardness, thermal, and electrical conductivity measurement. In addition, properties of OFHC copper (C10100) were evaluated in the annealed condition. OFHC copper represents the pure form of copper, and the effect of alloying elements $(\mathrm{Cu}-\mathrm{Cr}-$ $\mathrm{Zr}-\mathrm{Ti}$ ) can be better understood by comparison. Thermal conductivity was measured using a Flashline 3000 laser flash apparatus as the product of thermal diffusivity $(\alpha)$, specific heat $\left(\mathrm{C}_{p}\right)$, and density $(\rho)$. A disc of $12.7 \mathrm{~mm}$ diameter and $3 \mathrm{~mm}$ thickness was used for the measurement. The samples were made more opaque to the energy pulse by coating with 


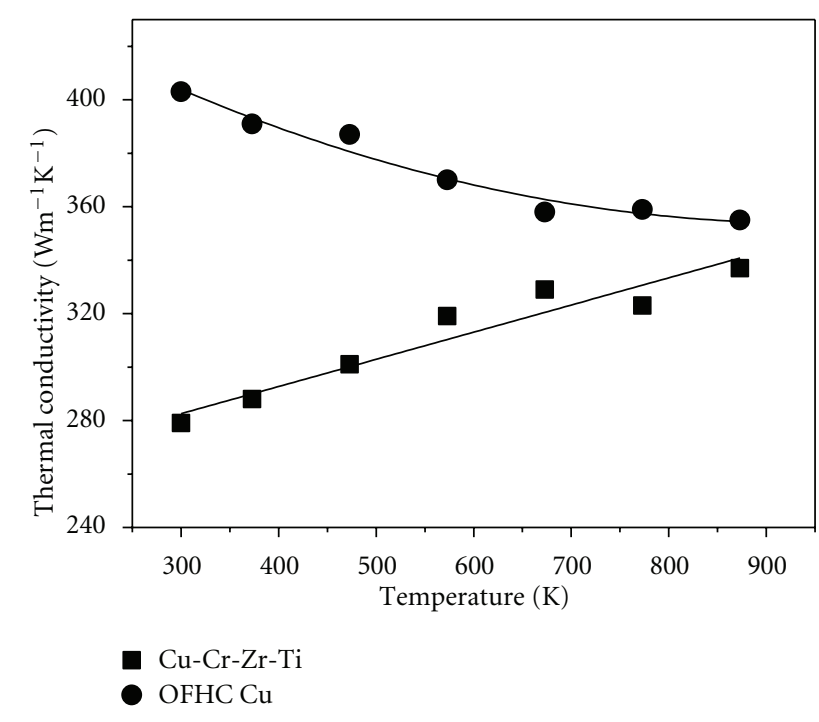

FIGURE 1: Effect of temperature on the thermal conductivity of OFHC copper and $\mathrm{Cu}-\mathrm{Cr}-\mathrm{Zr}-\mathrm{Ti}$ alloy.

a thin layer of graphite spray. Three tests were conducted in the temperature range of $300-873 \mathrm{~K}$, and average of three tests is reported. Hardness of the disc was measured at room temperature before and after thermal conductivity test using the Brinell Hardness Tester. An average of five hardness readings is reported. The electrical resistivity was determined using four-point technique by measuring the resistance of the specimens ( $50 \mathrm{~mm}$ (length) $\times 4 \mathrm{~mm}$ (width) $\times 6 \mathrm{~mm}$ (thickness)) utilizing meter calibrator-Wavetek 9100 and digital multimeter-HP 3458. Thin foils for TEM were prepared by mechanical polishing, dimpling, and ion milling. Discs of $3 \mathrm{~mm}$ diameter and $100 \mu \mathrm{m}$ thick were punched, and one side was dimpled followed by ion milling with an incident beam angle of $4^{\circ}$ using Gatan PIPS system. The ionmilled thin foils were examined under a JEOL transmission electron microscope operated at $200 \mathrm{kV}$.

\section{Results and Discussion}

Thermal conductivity of OFHC copper and $\mathrm{Cu}-\mathrm{Cr}-\mathrm{Zr}-\mathrm{Ti}$ alloy as a function of temperature is shown in the Figure 1. OFHC copper shows a decreasing trend with an increase in temperature, and $\lambda$ decreases from $397 \mathrm{Wm}^{-1} \mathrm{~K}^{-1}$ at $300 \mathrm{~K}$ to $350 \mathrm{Wm}^{-1} \mathrm{~K}^{-1}$ at $873 \mathrm{~K}$. The observed trend is in agreement with previous works [8-11]. On the other hand, $\lambda$ of $\mathrm{Cu}$ $\mathrm{Cr}-\mathrm{Zr}-\mathrm{Ti}$ alloy increases with increase in temperature up to $873 \mathrm{~K}$. The room temperature thermal conductivity was measured as $279 \mathrm{Wm}^{-1} \mathrm{~K}^{-1}$, while it reaches $337 \mathrm{Wm}^{-1} \mathrm{~K}^{-1}$ at $873 \mathrm{~K}$. The data obtained for OFHC copper and $\mathrm{Cu}-\mathrm{Cr}-\mathrm{Zr}-\mathrm{Ti}$ alloy could be correlated to a second degree polynomial and linear equation, respectively, as shown in Table 1.

It was also found that the thermal conductivity of $\mathrm{Cu}-\mathrm{Cr}-$ $\mathrm{Zr}$ - $\mathrm{Ti}$ alloy is lower than OFHC copper in the temperature range investigated. However, the gap between the curves was more at room temperature, and it diminished with increase in temperature. A similar increasing trend of thermal conductivity with temperature was reported in copper alloys $[9,10]$, platinum alloys [12], tungsten alloys [13], and magnesium alloys $[14,15]$. The reason for lower thermal conductivity for alloys can be attributed to the alloying elements added to the matrix. These elements impede the movement of free electrons, which are the primary source for heat transport in metals and alloys by acting as scattering sites and decreasing the mean free path [11]. Nevertheless, the magnitude of drop in thermal conductivity depends on the position of an element in the periodic table and the concentration of the element $[12,16]$.

The thermal conductivity of the metals and alloys is assumed to compose of an electronic component $\left(\lambda_{e}\right)$ and a phonon component $\left(\lambda_{p}\right)[13]$ :

$$
\lambda=\lambda_{e}+\lambda_{p}
$$

The electronic thermal conductivity can be approximately calculated using Wiedemann-Franz-Lorenz Law:

$$
\lambda_{e}=L \sigma T,
$$

where $L$ is the Lorentz number $\left(2.443 \times 10^{-8} \mathrm{~W} \Omega \mathrm{K}^{-2}\right), \sigma$ is the electrical conductivity $(\Omega \mathrm{m})^{-1}$, and $T$ is temperature $(\mathrm{K})$

$$
\begin{aligned}
& \lambda_{e}(\mathrm{Cu}-\mathrm{Cr}-\mathrm{Zr}-\mathrm{Ti}) \\
& \quad=\left(2.443 \times 10^{-8}\right) \cdot\left(0.3386 \times 10^{8}\right) \cdot 300 \\
& \quad=248 \mathrm{Wm}^{-1} \mathrm{~K}^{-1} .
\end{aligned}
$$

$\lambda_{p}(\mathrm{Cu}-\mathrm{Cr}-\mathrm{Zr}-\mathrm{Ti})$ is calculated as $31 \mathrm{Wm}^{-1} \mathrm{~K}^{-1}\left(\lambda-\lambda_{e}: 279-\right.$ $248)$. This indicates that the electron contribution is dominant for the alloy at room temperature.

It is noteworthy to mention that the addition of impurities largely reduces the electronic thermal conductivity $\left(\lambda_{e}\right)$ of the alloy. This can be substantiated by comparison of $\lambda_{e}$ for OFHC copper and $\mathrm{Cu}-\mathrm{Cr}-\mathrm{Zr}-\mathrm{Ti}$ alloy at room temperature. The $\lambda_{e}$ obtained for OFHC copper and $\mathrm{Cu}-\mathrm{Cr}-\mathrm{Zr}$-Ti alloy was $398 \mathrm{Wm}^{-1} \mathrm{~K}^{-1}$ and $248 \mathrm{Wm}^{-1} \mathrm{~K}^{-1}$, respectively, which clearly shows that $\lambda_{e}$ for the alloy is suppressed due to alloying elements. This result is in line with that obtained for MgSc alloys, where it was reported that significant change has been noticed in $\lambda_{e}$ with the concentration of the alloying element added to the alloy $[14,15]$.

It is seen from the Figure 1 that the thermal conductivity of $\mathrm{Cu}-\mathrm{Cr}-\mathrm{Zr}$-Ti alloy increases with temperature up to $873 \mathrm{~K}$. The reason for such increasing trend to a larger extent may be attributed to the increase in electronic thermal conductivity with temperature [13-15]. Nevertheless, some contribution can be ascribed to microstructural changes occurring in the specimen during the test. The alloy studied can attain age hardening in the temperature range of 673-823 K $[3,4]$. In the present study, tests were conducted in the temperature range of $300-873 \mathrm{~K}$ and at each test temperature, and the sample was held for $30 \mathrm{~min}$ for attaining homogeneity. Therefore, there is a reason to believe that in situ aging might have occurred, which has contributed to the increase in thermal conductivity with temperature. This argument was supported by measuring the hardness of the disc after the 
TABLE 1: Results of regression analysis for $\alpha, C_{p}$, and $\lambda$ and temperature for OFHC copper and Cu-Cr-Zr-Ti alloy.

\begin{tabular}{lcccc}
\hline Property & Material & Equation & Regression constant $\left(R^{2}\right)$ & Valid range \\
\hline \multirow{2}{*}{ Thermal conductivity $(\lambda)$} & OFHC Cu & $\lambda=461.1-0.22(T)+1.20 \times 10^{-4}\left(T^{2}\right)$ & 0.9490 & $300-873 \mathrm{~K}$ \\
& $\mathrm{Cu}-\mathrm{Cr}-\mathrm{Zr}-\mathrm{Ti}$ & $\lambda=253.5+0.099(T)$ & 0.9123 & $300-873 \mathrm{~K}$ \\
\hline
\end{tabular}

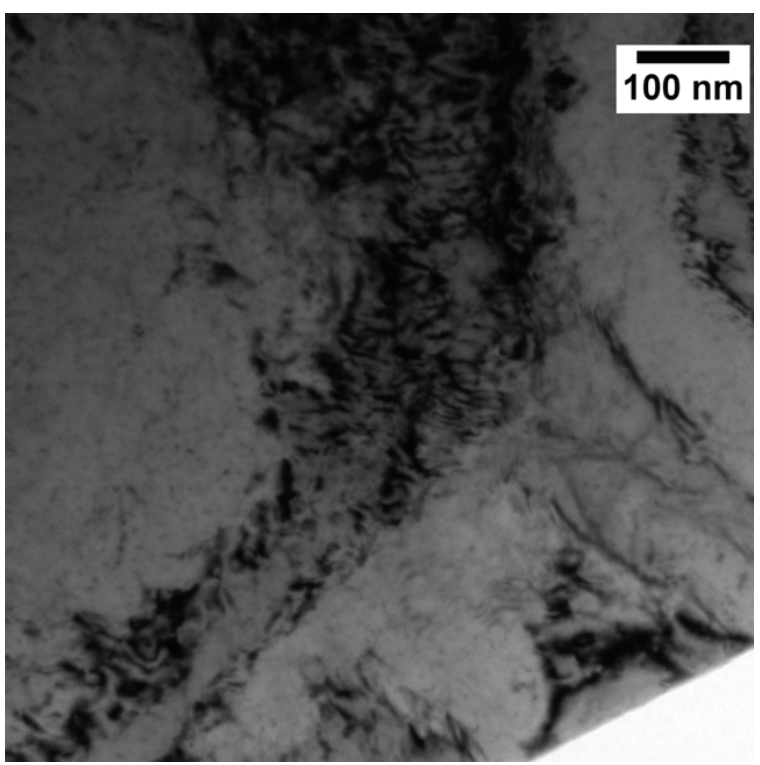

(a)

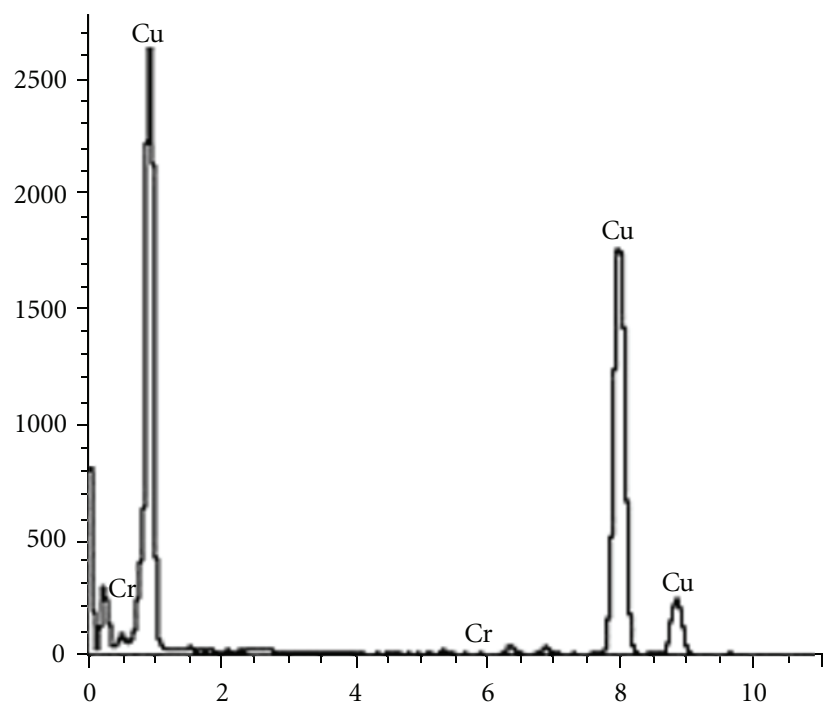

(c)

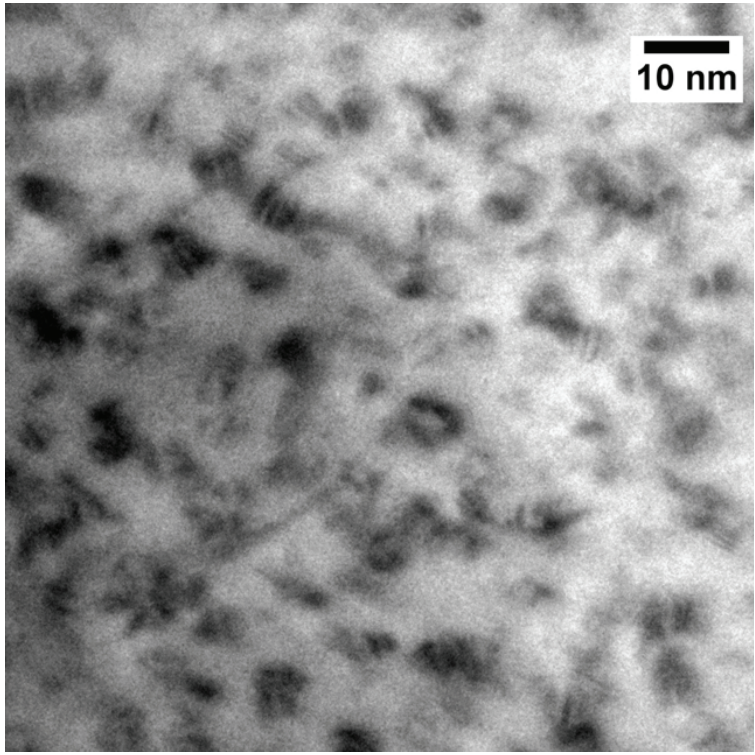

(b)

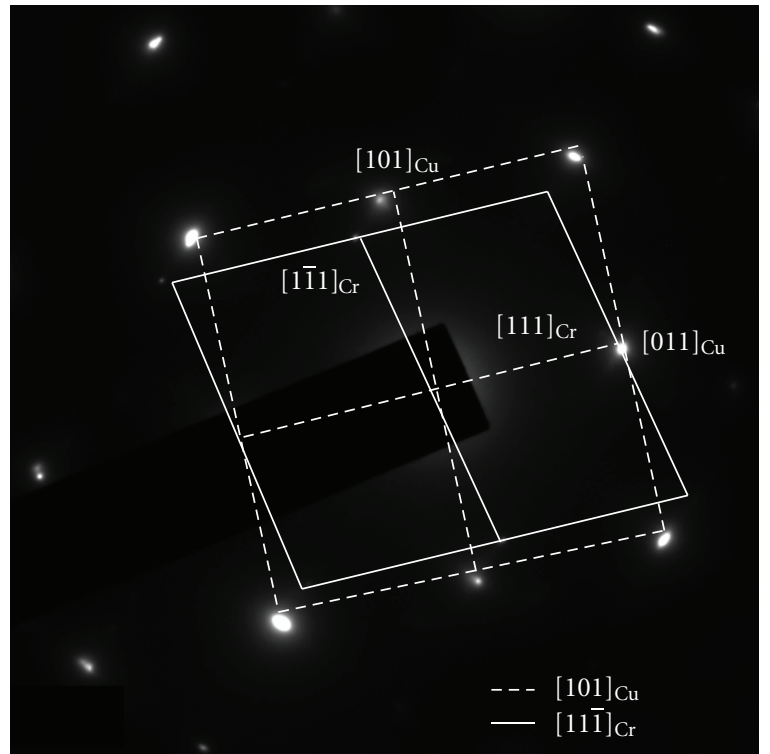

(d)

FIGURE 2: Transmission electron microscopy images of thermal conductivity specimens (a) before test, (b) after test, (c) EDS spectrum from (a), and (d) selected area diffraction from (b).

test. The hardness of the disc before the thermal conductivity test was $70 \mathrm{BHN}$, and after the test, it has increased to $91 \mathrm{BHN}$, which shows that hardening has occurred in the sample. The possible mechanism which enables hardening in the given temperature range of the alloy is in situ aging. In situ aging will result in the precipitation of excess element, which will make the matrix pure (rich in $\mathrm{Cu}$ ), and increases the thermal conductivity.

The transmission electron microscopy images of the thermal conductivity specimens before and after the test are shown in Figure 2. The bright-field image of the specimen before the test is shown in Figure 2(a) with modulated 
structure free of any precipitates. Figure 2(b) shows the bright-field image of the specimen after the test where a uniform distribution of fine precipitates is observed in the matrix. The energy dispersive X-ray spectroscopy (EDS) analysis spectrum obtained from the sample before the test (Figure 2(a)) is shown in Figure 2(c). The spectrum shows prominent peaks of copper with few peaks of chromium. From the spectrum, it can be inferred that the sample is in the solution treated condition with excess chromium in the copper matrix. The selected area diffraction (SAD) pattern taken from Figure 2(b) is shown in Figure 2(d). The spot pattern obtained was solved and indexed for matrix and precipitate. The matrix had FCC crystal structure corresponding to copper, and precipitate has BCC crystal structure corresponding to chromium. The matrix and precipitate are indicated with subscripts $\mathrm{Cu}$ and $\mathrm{Cr}$, respectively. From TEM studies, it is inferred that precipitates that form in the specimen after the test is chromium precipitates, and similar Cr precipitates were reported by Batra et al. [3, 4]. In addition to hardness measurement, TEM studies clearly confirm the occurrence of in situ aging in the specimen after the test.

\section{Conclusions}

The investigation of thermal conductivity of $\mathrm{Cu}-\mathrm{Cr}-\mathrm{Zr}-\mathrm{Ti}$ alloy in the temperature range of $300 \mathrm{~K}-873 \mathrm{~K}$ showed that the thermal conductivity is sensitive to temperature. With an increase in temperature, thermal conductivity showed an increase up to $873 \mathrm{~K}$. Thermal conductivity increased by $20 \%$ at $873 \mathrm{~K}$ compared to that at room temperature. In addition to electronic thermal conductivity, one of the reasons for the increasing trend with temperature is in-situ aging of the sample which results in formation of precipitates and facilities precipitation of excess solute from the matrix. The curve obtained for thermal conductivity could be modeled to a linear equation. Electronic and phonon thermal conductivity of the alloy was calculated using Wiedemann-Franz-Lorenz law, and it was found that the phonon contribution was insignificant at room temperature.

\section{Acknowledgment}

The authors express their sincere gratitude to the director of VSSC for his kind permission to publish this paper.

\section{References}

[1] G. J. Butterworth and C. B. A. Forty, "A survey of the properties of copper alloys for use as fusion reactor materials," Journal of Nuclear Materials, vol. 189, no. 3, pp. 237-276, 1992.

[2] H. Groh, D. Ellis, and W. Loewenthal, "Comparison of GRCop-84 to other $\mathrm{Cu}$ alloys with high thermal conductivities," Journal of Materials Engineering and Performance, vol. 17, pp. 594-606, 2008.

[3] I. S. Batra, G. K. Dey, U. D. Kulkarni, and S. Banerjee, "Microstructure and properties of a Cu-Cr-Zr alloy," Journal of Nuclear Materials, vol. 299, no. 2, pp. 91-100, 2001.
[4] I. S. Batra, G. K. Dey, U. D. Kulkarni, and S. Banerjee, "Precipitation in a Cu-Cr-Zr alloy," Materials Science and Engineering A, vol. 356, pp. 32-36, 2003.

[5] H. Fuxiang, M. Jusheng, N. Honglong et al., "Analysis of phases in a Cu-Cr-Zr alloy," Scripta Materialia, vol. 48, no. 1, pp. 97-102, 2003.

[6] R. D. K. Misra and V. S. Prasad, "On the dynamic embrittlement of copper-chromium alloys by sulphur," Journal of Materials Science, vol. 35, no. 13, pp. 3321-3325, 2000.

[7] R. D. K. Misra, V. S. Prasad, and P. R. Rao, "Dynamic embrittlement in an age-hardenable copper-chromium alloy," Scripta Materialia, vol. 35, no. 1, pp. 129-133, 1996.

[8] P. Hanzelka, V. Musilova, T. Kralik, and J. Vonka, "Thermal conductivity of a CuCrZr alloy from $5 \mathrm{~K}$ to room temperatures," Cryogenics, vol. 50, no. 11-12, pp. 737-742, 2010.

[9] T. M. Tritt, Thermal Conductivity: Theory, Properties, and Applications, Plenum Press, New York, NY, USA, 2004.

[10] R. C. Smith, "Thermal conductivity of copper alloys.-I. Copper-zinc alloys," Trans AIME Papers, vol. 102, pp. 3-24, 1930.

[11] R. C. Smith and W. K. Palmer, "Thermal and electrical conductivities of copper alloys," Trans AIME Papers, vol. 221, pp. 225-241, 1935.

[12] D. E. Gray, American Institute of Physics Handbook, McGrawHill, New York, NY, USA, 1972.

[13] Y. Terada, K. Ohkubo, T. Mohri, and T. Suzuki, "Thermal conductivity in Pt-based alloys," Journal of Alloys and Compounds, vol. 285, no. 1-2, pp. 233-237, 1999.

[14] T. Tanabe, C. Eamchotchawalit, C. Busabok, S. Taweethavorn, M. Fujitsuka, and T. Shikama, "Temperature dependence of thermal conductivity in $\mathrm{W}$ and W-Re alloys from 300 to 1000 K," Materials Letters, vol. 57, no. 19, pp. 2950-2953, 2003.

[15] A. Rudajevová, M. Staněk, and P. Lukáč, "Determination of thermal diffusivity and thermal conductivity of $\mathrm{Mg}-\mathrm{Al}$ alloys," Materials Science and Engineering A, vol. 341, no. 1-2, pp. 152157, 2003.

[16] A. Rudajevová, F. von Buch, and B. L. Mordike, "Thermal diffusivity and thermal conductivity of MgSc alloys," Journal of Alloys and Compounds, vol. 292, pp. 27-30, 1999. 

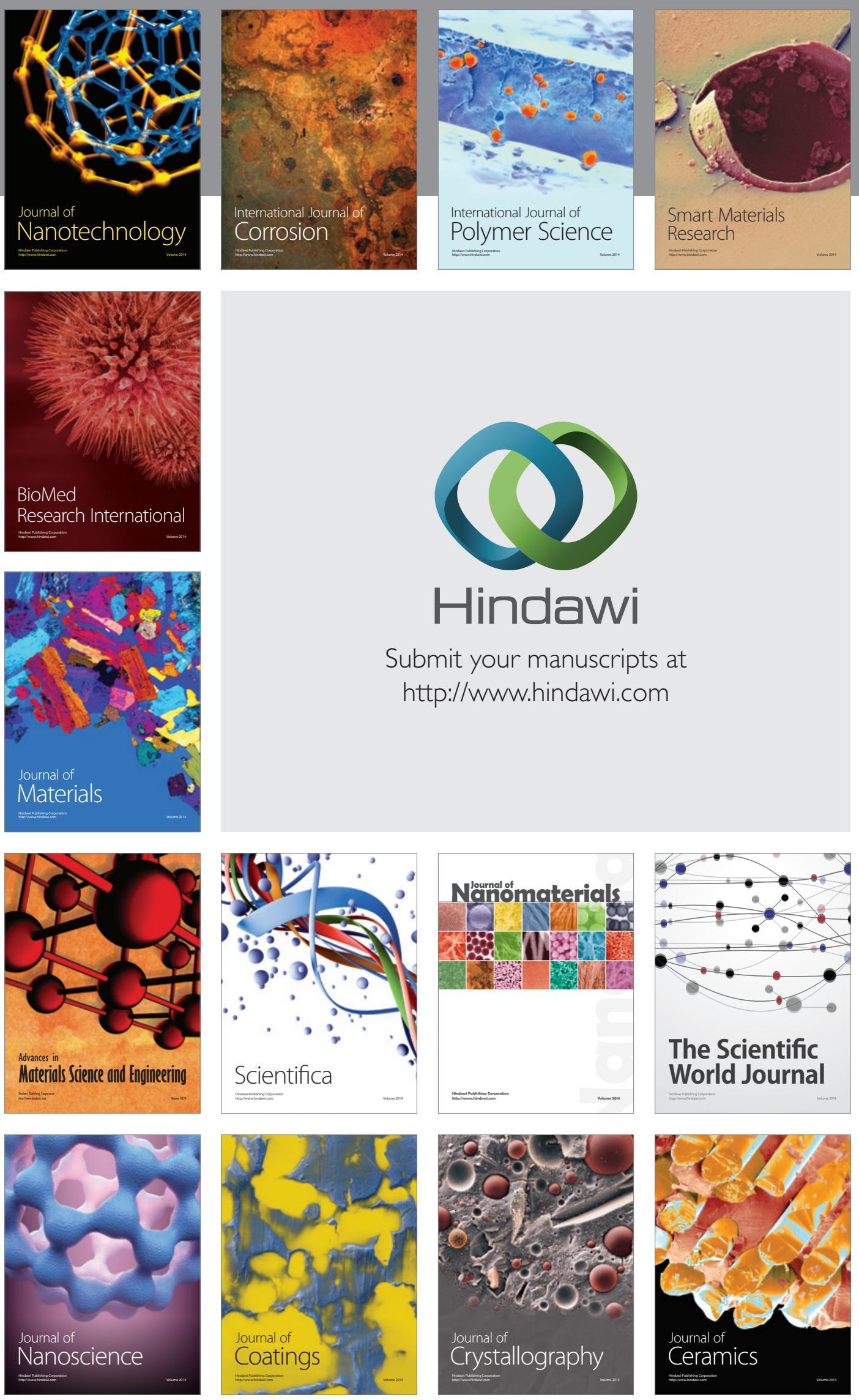

The Scientific World Journal

Submit your manuscripts at

http://www.hindawi.com

\section{World Journal}

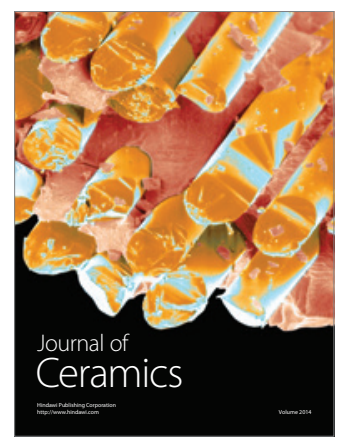

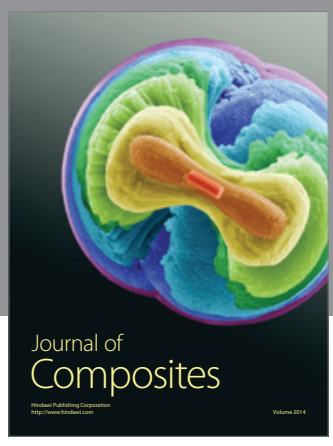
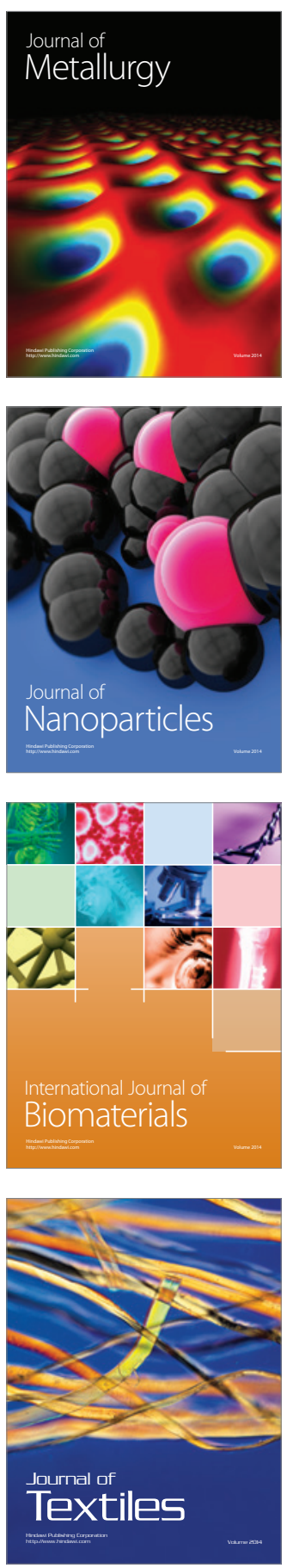